\title{
DECISION-MAKING STRATEGIES
}

\author{
BY
}

\section{JAMES NWOYE OBI, Ph.D. \\ "Decision-Making Strategies" . In C.P. Maduabum (Ed.) \\ Contemporary Issues on Management in Organizations: \\ A Book of Readings (Chapter 6, p.93). \\ Published by: Ibadan: Spectrum Books Limited}

\section{INTRODUCTION}

The word "decision-making" conjures up images of choice among alternative courses of action in a way appropriate to the demand of the situation. The ability of a decision maker to choose the best option that is capable of achieving the set objective or solving the problem demands structured decision guidelines. These guidelines put together are referred to as decision-making strategies.

The purpose of this chapter is to outline the most effective decision-making strategies which managers and leaders should follow in order to achieve the set goals of their organizations. They are action road-maps designed to minimize costs and maximize gains while, at the same time, leading the executive decision maker to the desired destination.

The chapter is divided into eight (8) sections as follows:

1. Conceptual clarification in which the key concepts running through the entire chapter are explained.

2. History of decision-making: Here, the origin of decision-making was traced up to the period when the term "decision-making" started serving as substitute for "resource allocation."

3. Theories/Models/Process of Decision-making. Various theories and models of decisionmaking are discussed in this section. A clear distinction is also made between "decision" and "decision-making." Decision implies the passing of judgment on an issue under consideration while decision-making is the process of reaching this consensus judgment 
4. Typology of decision-making explains the various types of decision individuals and organizations make towards different programmes, problems and objectives.

5. Decision-making strategies are the structured methods and operational guidelines followed by decision makers to make better decisions.

6. Challenges facing decision makers: Here, the challenges and difficulties facing a decision maker in various situations are discussed.

7. Hidden traps in decision making: There are traps and pitfalls that must be avoided by executive decision makers if they are to make better decisions that would move their organizations forward. These traps and dangers were highlighted in this section.

8. The concept of "ugly decision problem" and "nice decision problem." This is a new concept in decision making. According to this concept, decision problems can be divided into two parts. One part involves problems, worry and anxiety while the other part is largely pleasurable and easy-going.

\section{CONCEPTUAL CLARIFICATION}

When we talk about decision-making, we are referring to the choice we have made after giving careful thought to an issue. Decision-making itself is the process of making a choice from among various alternative courses of action. It is a choice from multiple options open to the decision maker. The essential issue is to choose the best alternative route that is capable of delivering the goods for the organization at minimum cost. Certainly, decision-making involves choice from a basket of alternatives. However, more often than not, the problem upon which decision is to be made vary in importance, magnitude or gain to the organization. For this reason, we have strategic and non-strategic decisions.

Strategic decisions are those decision elements that determine the overall direction of an enterprise, taking into consideration the predictable and unpredictable changes that may occur in the business environment of the organization. They involve substantial investment of resources (Gillingham, 2003: 95). Non-strategic decisions, on the other hand, constitute day-to-day minor decisions guiding activities and operations in the enterprise. Such decisions do not touch the entire soul and life of the organization. 


\section{HISTORY OF DECISION-MAKING}

Sometime in the middle of the 18th century, Chester Bernard, a retired telephone executive and author of The Functions of the Executive imported the term "decision-making" from the lexicon of public administration into the business world. There it began to replace narrower descriptions such as "resource allocation" and "policy making" (Buchanan, 2006: 32). The introduction of that phrase changed how managers thought about what they did and spurred a new sense of action and desire for conclusiveness on the part of managers. 'Decision' implies the end of deliberation and the beginning of action.

Bernard and such later theorists as James March, Herbert Simon, and Henry Mintzberg laid the foundation for the study of managerial decision making. The study of decision making consequently is an intellectual discipline bringing together mathematics, sociology, psychology, economics, and political science. Philosophers ponder what our decisions say about ourselves and about our values and historians dissect the choices leaders make at critical junctures. Research into risk and organizational behavior springs from a more practical desire aimed at helping managers to achieve better outcomes. While a good decision does not guarantee a good outcome, such pragmatism has paid off. A growing sophistication with managing risk, better understanding of human behavior, and advances in technology that supports cognitive processes have improved decision making in many situations Albert (Camus, 2006: 30).

The history of decision-making strategies is not one of unalloyed progress towards perfect rationalism. Over the years, we have steadily been coming to terms with constraints - both contextual and psychological - on our ability to make optimal choices. Some decision authorities are of the opinion that complex circumstances, limited time, and inadequate mental computational power reduce decision makers to a state of "bounded rationality." Others argue that people would make economically rational decisions if only they could gather enough information.

The Administrative Behaviour theory of decision-making as put forward by Herbert A. Simon (2001), centred on the study of decision-making process in administrative organizations. The author was of the opinion that decision-making is the heart of administration and that the vocabulary of administrative theory must be derived from the logic and psychology of human 
choice. He attempted to describe administrative organizations in a way that provides the basis for scientific analysis. The author rejected the notion of an omniscient "economic man" capable of making decisions that can bring the greatest possible benefit. He rather substituted the notion with the idea of "administrative man" who optimizes rather than maximizes his decision effort. He argued that, there is no one way of managing or one best decision. He was strongly of the view that the decision we make is just good enough and not the best because of subjective human elements intervening in decision-making process. He therefore concluded that the decision we make is "satisfying" that is good enough rather than "maximizing" that is the best decision. This is buttressed by the concept of "Bounded Rationality." Bounded rationality is the idea that rationality of individuals is limited by the information available to them at the time of decisionmaking - the cognitive limitations of their mind. Decision makers (irrespective of their level of intelligence) have to work under three unavoidable constraints: (a) limited information available to the decision maker, (b) limited capacity of the human mind to evaluate situations, (c) limited amount of time available for making decisions.

James March (1963), carried out a seminal work on the behavioural perspective on the theory of the firm which explained the systemic-anarchic model of organizational decision-making known as Garbage Can Model. The scope of his work was broad but focused on understanding how decisions happen in individuals, groups, organizations, companies and society. Henry Mintzberg in his ground-breaking article titled The Nature of Managerial work (1973) went on to set the stark reality of what managers do. He was of the opinion that pressure of the job drives the manager into taking too much work load, encouraging interruptions, responding quickly to every stimulus, seeking the tangible and avoiding the abstract, making decisions in small increments, and doing everything abruptly. Mintzberg proposed six characteristics of managerial work. These characteristics apply to all management jobs, from supervisor to chief executive. The six characteristics are:

1. The manager's job is a mixture of regular, programmed jobs and unprogrammed tasks.

2. A manager is both a generalist and a specialist.

3. Managers rely on information from all sources but show a preference for that which is orally transmitted.

4. Management work is made up of activities that are characterized by brevity, variety and fragmentation. 
5. Management work is more of an art than a science and it is reliant on intuitive processes. 6. Management work is becoming more complex.

\section{THEORIES/MODELS/PROCESS OF DECISION-MAKING}

Probability model of Decision-making: Most of the managerial decisions are decisions related to uncertainty. Tomorrow is not well defined. Managers are required to make some appropriate assumptions for the "would be tomorrow" and base their decisions on such assumptions. The notion of uncertainty or chance is so common in everybody's life that it becomes difficult to define it. We talk about chances of one winning the election, chances of one getting a wellpaying job, marrying a beautiful wife or a handsome husband. In fact, almost everything happening in our day to day life is a matter of chance. Some people would prefer to call it "luck" others would say that, under uncertainty man is forced to gamble. That is, under uncertainty a decision maker is forced to take risk. Statistically speaking, we attach probability with the occurrence or non-occurrence of an event.

The Decision Tree Model: The decision tree model involves choosing by projecting expected outcomes. Decision trees are excellent tools for helping decision makers to choose between several courses of action. They provide a highly effective structure within which you can lay out options and investigate the possible outcomes of choosing those options. They also help decision makers to form a balanced picture of the risks and rewards associated with each possible course of action.

The Games Model of Decision-Making: The games model is the study of strategic decision making. More formally, it is the study of mathematical models of conflict and cooperation between intelligent rational decision-makers. Games theory is a type of decision theory in which ones choice of action is determined after taking into account all possible alternatives available to an opponent playing the same game, rather than just by the possibilities of several outcomes.

Games theory is mainly used in economics, political science, and psychology, as well as logic and biology. The subject first addressed Zero-sum games, such that one person's gains exactly equal net losses of the other participant.

\section{The Processes of Decision-Making}

Both for profit making firms and non-business organizations, the process of decision-making can be divided into five basic steps as follows: 
Step 1 - Establish or Identify the Objectives: In making any decision, you, as the decision maker, should determine what the organization's (or individual's) objectives are. Unless you know what it is that you are trying to achieve, there is no sensible way to make the decision. For example, consider the managers of Black and Decker - the power tool manufacturer, who had to decide in the 1970s whether the firm's consumer power tools should be re-designed. Their objectives were to bolster the company's profits, to attain a $15 \%$ annual growth rate, to remain independent, and to service world markets (Mansfield, 1999: 8).

Step 2 - Define the problem: One of the most difficult parts of decision making is to determine exactly what the problem is. Frequently, executives confront a situation that is judged to be unsatisfactory. For instance, the management of the same Black and Decker Company felt that they had to change their operations drastically if they were to continue to be a domestic manufacturer doing business internationally. To meet this challenge, they had to determine exactly what the problem was, since otherwise, they had little chance of solving it. After considerable study, they concluded that the problem was the likelihood of increased foreign competition and the possibility that double insulation of power tools would be legally required. (Double insulation means that an additional insulation barrier is required and this will be placed in an electric device to protect the user from electric shock if the main insulation system fails). Step 3 - Identify Possible Options: Once the problem is defined, you should try to construct and identify possible options. For example, Black and Decker considered a variety of options, including more effective production and marketing of its products based on existing designs, as well as, re-designing its entire product line.

Step 4 - Select the Best Possible Option: having identified the set of alternative possible options, you must evaluate each one and determine the best option, given the objectives of the organization. In the case of Black and Decker, studies indicated that the best solution was to redesign the firm's consumer power tools. Black and Decker's managers decided that a window of opportunity existed to improve their product lines and manufacturing capability. Moreover, they decided that, if they did not take time to do it right the first time, they would never have the time or resources to do it again. 
Step 5 - Implement the Option: Once a particular option has been chosen, it must be implemented right away in order to be effective. Even organizations as disciplined as the armies find it difficult to carry out orders effectively. Since, even the best options can come to naught if they are not carried out. This phase of the decision-making process is of crucial importance. In the case of Black and Decker, the organization of the firm was changed, and a new job - Vice President of Operations - was created so that manufacturing engineering were all under one manager. The firm's top management made sure the decision was implemented properly. (Mansfield, 1999: 10).

\section{TYPOLOGY OF DECISION}

Decisions made by organizations and individuals can be grouped into different types. They show the nature, importance, duration and areas which a particular decision can cover in an organization or in an individual's private life. There are four distinct types of decision:

\section{Programmed and non-programmed decisions}

Decisions made by managers fall into two major categories referred to as "programmed" and "non-programmed" decisions. Programmed decisions are those that are applied to routine situations that occur often. They are structured in the sense that decision rules and procedures are available which can be used again and again. Examples of programmed decisions include pricing, regular customer's orders, determining the salary of employees, etc.

Non-programmed decisions are new and different from situations experienced in the past. Thus, there are no standard methods that are appropriate to the particular situation. The problems upon which the decisions are made are unstructured. The managers must apply sound judgment, initiative and creative thinking. Non-programmed decisions are rather complex and demand accurate facts and figures as well as precision (Chandra, 2001: 29). 


\section{Generic and Unique Decisions}

All decisions are not of equal importance. They can be categorized as generic or unique decisions. The relative importance and nature of each decision can be measured in the following ways:

Decision duration: A decision that has long range implications into the future should be considered as unique. Example of such decisions include; replacement of machinery and diversification of product lines.

Impact of a decision on other functional areas: The decision to change the apportionment and allocation of overheads to various departments is a unique decision.

Qualitative factors inherent in the decision: A decision which involves some qualitative factors is an important decision and therefore should be considered as unique decision.

Frequency of decision: Decisions which are unique to a situation, which rarely repeat themselves are regarded as unique decisions.

Generic decisions, on the other hand, have less adverse consequences. They do not require heavy investment outlay. More often than not, they do not involve much risks and danger.

\section{Routine and Non-routine Decisions}

Routine decisions are the day-to-day decisions which are supportive to the effective operation of an organization. They are not central to the life of the organization. They relate to the present. Routine decisions aim to achieve efficiency in the operations of the company. Routine decisions include provision of air conditioning, better lighting and ventilation, employee housing and the provision of other facilities.

Non-routine (or strategic decisions) on the other hand, are important decisions affecting the very life and survival of an organization. They are futuristic in nature and have long term effects and implications on the business of the company. They also involve a lot of investments and risks. 
Decisions that affect product price, expansion of plant, automation of the production line and the like are regarded as non-routing decisions (Buchanan, 2006)

\section{DECISION MAKING STRATEGIES}

Decision-making is the process of identifying and choosing among alternative courses of action in a manner appropriate to the demands of the situation (Kreitner, 2007: 26). A decision is a commitment to action. Every decision is risky. It is the commitment of present resources to an uncertain and unknown future. Experienced executives diagnose road-blocks to effective decision-making and develop strategies to overcome them. Effective decision-making demands precise and accurate strategies that would produce maximum success at all times. The strategies given here are time-tested strategies that have guided executives in successful decision-making. When making critical business decisions or contemplating strategic initiatives, the appropriate path to follow is rarely certain and nothing is crystal clear. The investment of valuable resources such as, people and funding are usually considerate. Uncertainty and ambiguity are continuous threats that present risks to the business and its shareholders. Seeing clearly through the haze of options can be immobilizing when the issues are complex and the stakes are high. Decision strategies bring clarity to the confusion.

\section{Decision Strategy for Addressing Complex problems}

More than a half century ago, two social scientists, James Thompson and Arthur Tuden, (1980:18) advanced what has come to be called "contingency theory" of decision making (Thompson and Tuden, 1959). They argued that there is a connection between two properties of problems - the degree of uncertainty and the extent of disagreement over trade-offs among important values - and the strategies appropriate for addressing those particular challenges. Although Thompson and Tuden developed a set of hypotheses about how different types of problems are to be solved, their theory is fundamentally normative, depending on the attributes of the problem at hand.

One class of problems termed messy, wicked, or ill-structured, is characterized by:

1. A high degree of uncertainty about how options are linked to outcomes and,

2. Substantial controversy over trade-offs among values. 
Examples of messy problems include preventing the spread of nuclear weapons, regulating the production and use of chemicals, and reforming the health care. Addressing such problems often require a mix of scientific research and engineering practice, which, by necessity, must be undertaken in a context of political disagreement.

\section{Decision Strategy for Addressing Well-Structured Problems}

If the level of uncertainty inherent in a problem is low and there is a strong consensus on values, decisions can be computed or sometimes even programmed. In such cases, choices follow directly from pre-established rules. Familiar forms of this decision-making strategy include costbenefit analysis, and optimization methods, such as the methods used in the operations research. Among the problems amenable to this strategy are determining a firm's tax liabilities or an individual's eligibility for welfare payments.

Although such programmed decision-making is always vulnerable to the criticism that it does not make allowances for exceptional or ambiguous cases or accounts for how (and by whom) costs and benefits are determined, this strategy is often sought by decision makers because it places great emphasis on efficiency.

\section{Bargaining as a Decision-making strategy}

If uncertainty is low but there are disagreements about trade-offs bargaining is the appropriate decision-making strategy. Bargaining can be effective in such cases because the understanding about connections between options and outcomes is sufficient for decision makers to appreciate how different alternatives affect salient values.

Common examples of this strategy include log-rolling by legislators, compromises in negotiations, and sensitivity testing in multi-attribute utility analyses. This strategy is also used in the writing of regulations, in deliberations on appropriation bills, and in adjusting social security payments to accommodate inflation. Because value trade-offs are inherently subjective, the stability of a bargain is, perhaps, the best measure of its success. 


\section{Incremental or Trial-and-Error Strategies}

An incremental strategy, otherwise known as trial-and-error decision making, is fitting for addressing problems characterized by substantial uncertainty and by a general consensus on values. Incremental strategies rely on "cybernetic" feedback model (Steinbruner, 1974). A decision is made and its impacts are closely monitored. When deviations from the desired outcome are discovered, adjustments are made. This process is repeated until the desired outcome is reached. Of course, irreversible outcomes at any stage doom this strategy. The effectiveness of an incremental approach depends on how well problem solvers can detect when actual outcomes deviate from the desired outcomes and how well they can find ways of making mid-course corrections.

\section{Brainstorming Strategy}

Brainstorming strategy was developed by Alex F. Osborn. Brainstorming is the oldest and best known technique for stimulating creative thinking. It involves the use of a group whose members are presented with a problem and are asked to develop as many potential solutions as possible. Members of the group may all be employees of the same or outside experts in a particular field. Brainstorming is based on the premise that when people interact in a free and uninhibited atmosphere they will generate creative ideas. That is, as one person generates an idea, it serves to stimulate the thinking of others. This interchange of ideas is supposedly contagious and creates an atmosphere of free discussion and spontaneous thinking. The objective is to produce as many ideas as possible in keeping with the belief that, the larger the number of ideas produced, the greater the probability of identifying an efficient and effective solution (Reddy, 2001: 30).

\section{Nominal Grouping strategy}

Developed by Andrew Van de Ven, nominal grouping differs from brainstorming strategy in two important ways. Nominal grouping does not rely on free association of ideas, and it attempts to reduce verbal interaction. From this latter characteristic, a nominal group is simply "a group in name only." Nominal grouping has been found to be particularly effective in situations requiring a high degree of innovation and idea generation. It generally follows a highly structured procedure involving different individuals coming from a multiplicity of backgrounds. 


\section{Creative Thinking strategy}

There are many ways of searching for information and alternatives in problem solving. Effective managers use all of their capacities - analytic, and creative, conscious and subconscious, and seek both individual and group involvement in this stage of decision making process. The basic requirement at the stage of identification of alternatives is to become more creative. Creativity involves novel combination of ideas which must have theoretical or social value or make an emotional impact on other people. In order to improve the quality and confidence you have in the decisions you make, as well as developing more trust in the decisions others make, consider the impact your emotions, vision and needs have on your decision making process.

\section{Managing Emotions and Outbursts}

Decision-making can be an emotional event. Emotions bog you down and becloud your ability to make good decisions. Medical science has shown that we make most of our decisions emotionally and not rationally. Science also suggests that $80 \%$ of what we think is wrong. Therefore, controlling your emotions and avoiding outbursts contribute to making better decisions. To do this, you must work on your emotional state. If you sometimes struggle with controlling your emotions, try these ideas:

\section{- When confronted with a decision, create a visual image of a blank slate.}

Your blank slate should be free of clutter or old thoughts and assumptions.

Try not to allow any other thoughts or feelings interfere with this image.

This blank slate represents your true starting point for making a proper and quality decision.

- Pay attention to your body's physical clues. Lower your voice, calm down and focus on not making any sudden moves. Stay in control to better control your ability to make a rational decision.

- Do not get too high or too low when confronted with a tough decision. Instead, try to visualize, in advance, the outcome of your decision. Consider what will be beneficial and what might be problematic.

- Practice. Just like refining your gold swing, the more you do anything, the better you become at doing it. 


\section{Creative Vision}

Your decisions are also formed by your vision. When you see something, clearly and personally, your opportunity to make a better decision is improved. Consider wearing seat-belts in your car. Many studies have proven, without a doubt, that a seat-belt can dramatically improve your chances of surviving a car accident. So, why do some people ignore this? The answer may be they have not visualized the outcome of their decision.

If someone you know refuses to wear a seat-belt, ask what he or she thinks would happen if he was travelling down the highway at $70 \mathrm{mph}$ and hit a tree? Ask him to visualize what this would look like. Perhaps, he would start making a different decision.

On a similar note, every year around the time for the school concert show our local high school puts a wrecked car in front of the building. The purpose for doing this is to give the administration the opportunity to show, or visualize, to the students what can happen if they drink and drive after the occasion. This technique is more powerful and effective than quoting statistics which may not be heard by the students. However, they do grasp what a wrecked car looks like and the tragic outcome of making the decision to drink and drive.

\section{Flip-Flopping as Decision-Making Strategy}

Decision implies the end of all deliberations on an issue and the beginning of action. Sometimes top executives find themselves in a situation where they have to suddenly alter a decision already taken and being implemented. This is called "flip-flopping" in decision making. Flip-flopping in decision making is not necessarily bad in itself. It is a way of saying: "I am wiser today than I was yesterday". This strategy is used to seize suddenly emerging business opportunity. This is especially true when flip-flopping is occasioned by advantages opening up in the business environment. Under such situation, it is wise to alter a decision in order to exploit business opportunity and make more profits for the firm. It therefore follows that a bit of flexibility should be built into every decision to enable the chief executive cash-in on opportunities in the interest of the organization. 


\section{CHALLENGES FACING DECISION MAKERS}

Decision making has never been easy, but it is especially challenging for today's managers. In an era of accelerating changes, the pace of decision making also has accelerated. In addition to having to cope with this acceleration, today's decision makers face a host of tough challenges. These challenges include a situation where they have to make complex streams of decisions, making decisions on the face of uncertainties, and facing perceptual and behavioural decision traps, (Kreitner, 2007: 30).

Dealing with Complex Streams of Decisions: Above all else, today's decision-making contexts are not so neat and tidy, but full of complexities and problems. A working knowledge of the following intertwined factors contributing to decision complexity can help decision makers successfully navigate rough decision making terrains.

(1) Multiple criteria: Typically, a decision today must satisfy a number of criteria representing the interests of different groups. Identifying stakeholders and balancing their conflicting interests is a major challenge for today's decision makers. It goes without saying therefore that a manager who aspires to be a good decision maker must also have a good grooming in "balancing act."

(2) Intangibles: Factors such as customer goodwill, employee morale, and increased bureaucracy often determine decision alternatives.

(3) Risk and uncertainty: Along with every decision alternative is the chance that it will fail in some way. Poor choices can prove costly. Yet the right decision can open up whole new vista of opportunities.

(4) Long-term implications: Major decisions generally have ripple effect, with one decision taken today creating the need for other decisions tomorrow. For example, an organization that takes a decision to open a bank account may later have to call another meeting to make a choice of the particular bank after the Chief Accountant would have submitted a report about a few bank studied and the facilities they can offer the organization. 
(5) Interdisciplinary input: Decision complexity is greatly increased when specialists such as lawyers, customer advocates, tax advisers, accountants, engineers, and production and marketing experts are to be consulted before making a decision. The views and fears of the different experts involved have to be analyzed, discussed and agreed upon before a decision is taken.

\section{THE HIDDEN TRAPS IN DECISION MAKING}

Behavioural scientists have identified some decision traps and some common human tendencies that are capable of eroding the quality of decision-making. Some of the important ones are discussed below. Awareness and avoidance of these traps can make executives better decision makers.

(1) Framing: One's judgment can be altered and reshaped by how information is presented or labeled. In other words, how information is presented influences one's interpretation of it. For example, you can use a bottle of honey which is filled up to the middle to create a positive or negative impression. This can be done by describing the bottle as "half-filled" to create positive impression or "half-empty" to create negative impression. This is called "framing."

Another example of the effect of framing is the result of a research carried out by a group of Medical Doctors on the use of a particular drug for medical treatment. The Doctors noted that when they reported that the drug had 50\% success, it led to increased use of the drug, but when the report said the drug recorded $50 \%$ failure, the demand for the drug dropped significantly.

(2) Overconfidence: The term overconfidence is commonplace and well-known that it does not require much of formal definition. Yet we need to comprehend the psychology

of overconfidence because it can expose managers to unreasonable risks.

Researchers have found a positive relationship between overconfidence and task difficulty. In other words, the more difficult a task is, the greater the tendency for people to be overconfident in executing the task. Easier and more predictable situations foster confidence, but generally not unrealistic overconfident. People may be overconfident about one or more of the following: accuracy, of input data, individual, team or organizational ability; and probability of success. 
There are various theoretical explanations for overconfidence. For example, overconfidence may often be necessary to generate courage needed to tackle difficult situations.

Before deciding on a course of action, prudent managers evaluate the situation confronting them. Unfortunately, some managers are cautious to a fault that is, taking costly steps to defend against unlikely outcomes. Other managers are over-confident making them to underestimate the range of potential outcomes. And yet others are highly impressionable, thus allowing memorable events in the past to dictate their view of what might be possible now (Hammond, 2009).

\section{The Anchoring Trap}

Anchoring is a mental phenomenon which leads the mind to give disproportionate weight or consideration to the first information it received. In other words, the initial impressions, estimates, data or opinion received anchor or condition subsequent thoughts and judgments. In business, one of the most common types of anchors is a past event or trend. A marketer attempting to project the sales of a product for the coming year often begins by looking at the sales volume for past years. Then old numbers become anchors, which the forecaster then adjusts based on other factors. This approach, while it may lead to a reasonably accurate estimate, tends to give too much weight to past events and not enough weight to other factors. In situations characterized by rapid changes in the market place, historical anchors can lead to poor forecasts and misguided choices.

\section{The Status-Quo Trap}

We all like to believe that we make decisions rationally and objectively. But the fact is that, we all carry biases, and those biases influence the choices we make. Decision makers display, for example, a strong bias toward alternatives that perpetuate the status quo. On a broad scale, we can see this tendency whenever a radically new product is introduced. The first "electronic newspapers" appearing on the world-wide-web looked very much like print precursors.

On a more familiar level, you may have succumbed to this bias in your personal financial decisions. People, sometimes, for example, inherit shares of stock that they would never have bought themselves. Although it would be a straightforward proposition to sell those shares and put the money into a different investment, a surprising number of people do not sell. They find the status quo comfortable, and they avoid taking action that would upset it. "May be I will rethink the matter later," they would say, but this "later" is usually never. 


\section{The Sunk-cost Trap}

Another deep-seated bias in decision-making is to make choices in a way that justifies or seeks to correct past bad choices. For instance, we may have refused to sell a stock or a mutual fund at a loss, therefore forgoing other more attractive investments. Or we may have spent enormous resources in an effort to improve the performance of an employee whose hire was a big error in the past. Our past wrong decision becomes what economists term "sunk cost" that is, retaining old wrong investment with hopeless hope. We know rationally that sunk-cost is irrelevant to the present decision, but nevertheless they prey on our minds, leading us to make inappropriate decisions.

Why are people not easily able to free themselves from wrong past decisions? It is because they are unwilling consciously or unconsciously to admit a mistake. Acknowledging a poor decision in one's personal life is purely a private matter, involving only one's self-esteem, but in business, a bad decision is often a very public matter, inviting critical comments from colleagues and bosses. If you fire a poor performer whom you hired in the past, you are making a public admission of your poor judgment in the past which should be sanctioned in the present. It seems psychologically safer for you to let him stay on, even though that choice only compounds the error.

The sunk-cost bias shows up with disturbing regularity in the banking sector, where it can have particularly dire consequences. When a borrower's business runs into trouble, a lender will often advance additional funds in the hope that the business will use that "bail-out" to recover. If the business succeeds in coming back to life, that is a wise investment. But if, unfortunately, the business continues to sink, the whole effort will be tantamount to throwing good money after a bad one. This issue is the cause of many bad debts and bank failures in the developing world. Because the bank manager has taken a part out of the customer's loan, he would not want the customer to be declared bankrupt or to allow the business to be liquidated. Instead he would continue to provide additional loans to prop up the lame business which has no hope of standing on its feet.

Sometimes, corporate culture reinforces the sunk cost trap. If the penalties for making a decision that leads to an unfavourable outcome are severe, managers will be motivated to let failed projects drag on endlessly, in the vain hope that they will somehow, in future be able to transform them into success. Executives should recognize that, in an uncertain world where unforeseen events are common, good decisions can sometimes lead to bad outcomes. By acknowledging that some good ideas will end in failure, executives will encourage people to cut their present losses rather than leaving them to mount. 


\section{THE CONCEPT OF "UGLY DECISION PROBLEM" AND “NICE DECISION PROBLEM"}

An organization does not just make decision into the thin air. Every decision is based on solving a particular problem in an organization. It could be performing a task, executing a project or procuring items for production. Traditionally, a problem is a situation or something that creates worry, inconvenience and discomfort to individuals and organizations. An organization will, first of all, identify the problem, define it, and then generate alternative courses of action for solving the problem. Decision will then be made on the choice of the alternative that has the highest probability of solving the problem.

Following latest research on decision making and problem solving, a new perspective has emerged on the scene of decision-making and problem solving. This is the concept of "ugly decision problem" and "nice decision problem." Ugly decision problem stands for a decision matter that creates, worry, inconvenience and trouble to the decision maker. On the other hand, a nice decision problem is one that does not create worry, inconvenience or trouble to the decision maker. They are elements of decision problems that give joy and satisfaction to the decision maker. The decision maker relaxes in his sofa chair happily while making the decision. Here is an example of a nice decision problem: Assuming you have a reasonable sum of money in your bank account and the problem you are having now is how to invest this money wisely to create additional wealth. This is certainly a nice decision problem (May-hall, 2009)

\section{CONCLUSION}

Decision-making involves choice from a basket of alternatives. It is the process of identifying and choosing among alternative courses of action. A decision is a commitment to action. Every decision is risky. It is the commitment of present resources to an uncertain and unknown future. Experienced executives diagnose road-blocks to effective decision-making and develop strategies to overcome them. Effective decision-making demands precise and accurate strategies that would produce the desired results. :

We have strategic and non-strategic types of decision. Strategic decisions are those decision elements that determine the overall direction of an enterprise. Non-strategic decisions, on the other hand, are day-to-day minor operational decisions in an organization. 
Effective decision-making demands precise and accurate strategies that would produce maximum success. Some of the strategies that can be used in decision-making include; bargaining, incremental or trial and error strategies, brainstorming, and nominal grouping. There are also hidden traps in decision-making which should be avoided by every decision maker. They include framing, overconfidence, anchor trap, status-quo trap and sunk-cost trap. Decision making has never been easy. It is especially challenging for today's managers. In an era of accelerating changes, the pace of decision making also has accelerated. In addition to having to cope with this acceleration, today's decision makers face a host of tough challenges. These challenges include a situation where they have to make complex streams of decisions, and making decisions on the face of uncertainties.

\section{REVIEW QUESTIONS}

1. List and discuss three Decision-Making Strategies you know.

2. What are the possible risks facing a corporate decision maker in the $21^{\text {st }}$ Century business environment?

3. Write short notes on four decision traps familiar to you.

4. What are the best decision-making strategies for successful University Administration ?

5. "It is better to make wrong decision than to make no decision at all." Discuss.

6. Why is decision-making necessary in every organization?

7. What do you understand by "flip-flopping" in decision-making? 


\section{REFERENCES}

Albert, C. (2006). Decision Making. Harvard Business Review, January.

Buchanan, L. (2006). Decision Making. Harvard Business Review, January.

Buchanan, L. (2006). Decision Making. Harvard Business Review, January.

Chandra, A. (2001) Management Decision Making. School of Management Studies, IGNOU Study Material, Printed (2001: 29)

Gillingham, R. (2003). Purchasing and Supply Chain Management ( $3^{\text {rd }}$ Edition) Pearson Educational Limited, Edinburgh Gate, Harlow, Essex CM20 2JE, England.

Kreitner, R. (2007). Principles of Management (Eleventh edition). (Canada), Nelson Educational Limited.

Kreitner, R. (2007). Principles of Management (Eleventh Edition). (Canada), Nelson Nelson Educational Limited.

Mansfield, E. (1999) Managerial Economics (Fourth edition). W.W. Norton \& Company Inc., 500 Fifth Avenue, New York NY 10110, U.S.A.

May-hall, B. (2009). Decision-making and Problem Solving.

Ph.D. Lecture Materials, Century University, New Mexico, U.S.A.

Steinburner, T. (1974). Decision-Making Strategies. School of Management Studies, IGNOU Study Material.

Ammeh, S. (2008). World Greatest Speeches in History (Benin City) Self-Improvement Publishing.

Hammond, J. (2006). The Hidden Traps in Decision-Making. Harvard Business Review, January.

Obi, J.N. (2011). The Making of an Expert Manager/Leader: Issues for Management and in the $21^{\text {st }}$ Century. International Journal of management Science, vol.3, no.3.

Simons, H. (1973). How Organizations Can be Understood in Terms of Decision-Making. http://www.google.com. Accessed February 8, 2013.

Williams, K.A. (1994). Decision-Making Techniques: How to make Better Decisions. http://www.google.com. Accessed, February 6, 2013. 